\title{
Do specific HLA antigens predispose to ischaemic heart disease or idiopathic dilated cardiomyopathy?
}

\author{
S C D Grant, S Sheldon, P A Dyer, R D Levy, N H Brooks
}

\begin{abstract}
Background-The aetiology of idiopathic dilated cardiomyopathy is believed to have an immunological component. Association with human leucocyte antigens (HLAs) has been previously reported, particularly with HLA-DR4.

Aim-To determine the association of HLA type with diagnosis in a group of patients assessed for heart transplantation.

Methods-A comparison was made of frequencies of HLA types in patients with a diagnosis of idiopathic dilated cardiomyopathy or $(n=98)$ ischaemic heart disease $(n=170)$ and in controls from the North Western region $(n=857)$.

Results-Neither the patients with idiopathic dilated cardiomyopathy nor those with ischaemic heart disease showed a significant increase or decrease in any HLA frequency compared with the controls.

Conclusion-These results suggest that there is no HLA association with idiopathic dilated cardiomyopathy or ischaemic heart disease. This conflicts with the results of some previous studies.
\end{abstract}

(Br Heart $\mathcal{F} 1994 ; 71: 76-78)$

The aetiology of idiopathic dilated cardiomyopathy remains elusive. Immunological factors are believed to play a part and some evidence exists to support this. Various abnormalities of $T$ lymphocyte function have been described including defects in natural killer $^{1}$ and suppressor lymphocyte function. ${ }^{23}$ Antimyocyte cytotoxic $\mathrm{T}$ cell responses, ${ }^{4}$ and autoantibodies to $\beta$ adrenoceptors ${ }^{5}$ and cardiac tissue ${ }^{6}$ have been identified.

Given the link between HLA types and other autoimmune diseases such as rheumatoid arthritis (HLA-DR4) and type I diabetes mellitus (HLA-DR3 and DR4), several studies have searched for an HLA association with idiopathic dilated cardiomyopathy. ${ }^{7-14}$ The most often reported association has been with HLA-DR4.

End stage ischaemic heart disease has been reported to be associated with HLA-DR6 in one study ${ }^{15}$ but this was not confirmed in another. ${ }^{8}$

\section{Patients and methods}

PATIENTS

We studied the HLA types in 98 patients with ischaemic dilated cardiomyopathy and 170 with ischaemic heart disease referred for heart transplantation. The control group comprised 857 people from north west England. Control frequencies were established by pooling data available from serological and molecular HLA typing of cadaveric organ donors (who were healthy immediately before their sudden death) and local healthy volunteer hospital staff.

HLA AND ALLELE TYPING

Patients and controls were typed for class I (HLA-A,B) and class II (HLA-DR) by routine serological methods. ${ }^{16}$ Also, restriction fragment length polymorphism typing was used to assign HLA-DR $\beta 1$ alleles, with restriction enzyme Taq 1 and probing Southern blots with restriction enzyme pRTV1. ${ }^{17}$

\section{STATISTICS}

Fisher's exact test was used for all comparisons and $p$ values were corrected for the number of comparisons made.

\section{Results}

No HLA type was significantly increased or decreased in frequency in idiopathic dilated cardiomypathy or ischaemic heart disease (tables 1-3). For idiopathic dilated cardiomyopathy there was a tendency for DR4 to be decreased $(26.5 \% v 35 \cdot 2 \%, \mathrm{p}=0.57)$ and for DR6 to be increased $(28.6 \% v 23.6 \%, \mathrm{p}=$ $0 \cdot 18$ ) by contrast with previous studies. Neither of these trends reached significance.

\section{Discussion}

We identified eight studies in which an HLA association with idiopathic dilated cardiomyopathy had been sought. ${ }^{7-14}$ The studies of

\section{Table 1 HLA-A frequencies}

\begin{tabular}{llll}
\hline$H L A$ & $\begin{array}{l}I D C \\
(\%, n=98)\end{array}$ & $\begin{array}{l}I H D \\
(\%, n=170)\end{array}$ & $\begin{array}{l}\text { Control } \\
(\%, n=632)\end{array}$ \\
\hline A1 & $40 \cdot 8$ & $33 \cdot 0$ & $33 \cdot 1$ \\
A2 & $53 \cdot 1$ & $45 \cdot 9$ & $49 \cdot 9$ \\
A3 & $27 \cdot 6$ & $31 \cdot 2$ & $33 \cdot 3$ \\
A9 & $18 \cdot 4$ & $14 \cdot 7$ & $15 \cdot 5$ \\
A10 & $4 \cdot 1$ & $7 \cdot 1$ & $8 \cdot 1$ \\
A11 & $7 \cdot 1$ & $11 \cdot 8$ & $11 \cdot 4$ \\
A19 & $21 \cdot 4$ & $23 \cdot 5$ & $29 \cdot 0$ \\
A28 & $6 \cdot 1$ & $11 \cdot 8$ & $5 \cdot 7$ \\
A36 & 0 & 0 & $0 \cdot 5$ \\
Single antigen & $21 \cdot 4$ & $21 \cdot 2$ & $16 \cdot 6$ \\
Detected & & &
\end{tabular}

IDC, idiopathic dilated cardiomyopathy; IHD, ischaemic heart disease. \\ Cardiology, \\ Hospital, Mancheste \\ R Levy \\ Typing Laboratory \\ Manchester \\ P A Dyer \\ Correspondence \\ Dr S C D Grant, \\ Wythenshawe Hospital \\ 14 September 1993
}


Table $2 \quad H L A-B$ frequencies

\begin{tabular}{|c|c|c|c|}
\hline$H L A$ & $\begin{array}{l}I D C \\
(\%, n=98)\end{array}$ & $\begin{array}{l}I H D \\
(\%, n=170)\end{array}$ & $\begin{array}{l}\text { Control } \\
(\%, n=632)\end{array}$ \\
\hline B5 & $11 \cdot 2$ & $8 \cdot 2$ & $5 \cdot 5$ \\
\hline B7 & $27 \cdot \overline{6}$ & $24 \cdot 7$ & 26.9 \\
\hline B8 & $24 \cdot 5$ & $24 \cdot 7$ & $24 \cdot 5$ \\
\hline B12 & $31 \cdot 6$ & $32 \cdot 4$ & $35 \cdot 3$ \\
\hline B13 & $3 \cdot 1$ & 5.9 & $3 \cdot 8$ \\
\hline B14 & $8 \cdot 2$ & $7 \cdot 1$ & $6 \cdot 0$ \\
\hline B15 & $11 \cdot \overline{2}$ & $14 \cdot 1$ & $13 \cdot 6$ \\
\hline B16 & $5 \cdot 1$ & 3.5 & 3.8 \\
\hline B17 & $8 \cdot 2$ & $10 \cdot 6$ & $11 \cdot 1$ \\
\hline B18 & $6 \cdot 1$ & $5 \cdot 9$ & $8 \cdot 7$ \\
\hline B21 & $10 \cdot 2$ & $1 \cdot 8$ & $5 \cdot 1$ \\
\hline B22 & $4 \cdot 1$ & $8 \cdot 8$ & $5 \cdot 4$ \\
\hline B27 & $9 \cdot 2$ & $7 \cdot 1$ & $7 \cdot 1$ \\
\hline B35 & $7 \cdot 1$ & $12 \cdot 4$ & $10 \cdot 4$ \\
\hline B37 & $2 \cdot 0$ & $2 \cdot 9$ & $3 \cdot 2$ \\
\hline B40 & $11 \cdot 2$ & $12 \cdot 4$ & $12 \cdot 5$ \\
\hline B41 & $1 \cdot 0$ & $2 \cdot 9$ & $1 \cdot 7$ \\
\hline B47 & $1 \cdot 0$ & $2 \cdot 4$ & $1 \cdot 0$ \\
\hline B53 & $1 \cdot 0$ & 0.6 & $0 \cdot 1$ \\
\hline B59 & 0 & 0 & $1 \cdot 0$ \\
\hline B70 & 0 & 0 & 0.5 \\
\hline Single antigen & $16 \cdot 3$ & $11 \cdot 8$ & $11 \cdot 1$ \\
\hline
\end{tabular}

See footnote to table 1 for abbreviations.

Table 3 HLA-DR frequencies

\begin{tabular}{|c|c|c|c|}
\hline$H L A$ & $\begin{array}{l}I D C \\
(\%, n=98)\end{array}$ & $\begin{array}{l}I H D \\
(\%, n=170)\end{array}$ & $\begin{array}{l}\text { Control } \\
(\%, n=857)\end{array}$ \\
\hline $\begin{array}{l}\text { DR1/103 } \\
\text { DR2 } \\
\text { DR3 } \\
\text { DR4 } \\
\text { DR5 } \\
\text { DR6 } \\
\text { DR7 } \\
\text { DR8 } \\
\text { DR9 } \\
\text { DR10 } \\
\text { Single antigen } \\
\text { Detected }\end{array}$ & $\begin{array}{r}19 \cdot 3 \\
33 \cdot 7 \\
24 \cdot 5 \\
26 \cdot 5 \\
11 \cdot 2 \\
28 \cdot 6 \\
28 \cdot 6 \\
5 \cdot 1 \\
3 \cdot 1 \\
2 \cdot 0 \\
17 \cdot 3\end{array}$ & $\begin{array}{r}19 \cdot 4 \\
27 \cdot 1 \\
28 \cdot 8 \\
29 \cdot 4 \\
18 \cdot 8 \\
28 \cdot 2 \\
25 \cdot 9 \\
2 \cdot 9 \\
1 \cdot 2 \\
2 \cdot 4 \\
15 \cdot 9\end{array}$ & $\begin{array}{r}19 \cdot 3 \\
28 \cdot 4 \\
28 \cdot 8 \\
35 \cdot 2 \\
12.7 \\
23 \cdot 6 \\
26.3 \\
3.5 \\
1.9 \\
1.4 \\
18.9\end{array}$ \\
\hline
\end{tabular}

See footnote to table 1 for abbreviations.

Anderson et al ${ }^{12}$ and Carlquist et $a l,{ }^{11}$ and those of Arbustini et $a l^{10}$ and Carforio et $a l^{13}$ are from the same groups. The second papers from each group contain and expand on data from the earlier studies. Carlquist et al ${ }^{11}$ also performed a meta-analysis of five of the studies. $^{7-11}$ Two studies ${ }^{1314}$ have been published since the meta-analysis was submitted, and we have submitted most of the data presented here in abstract form, ${ }^{18}$ as have another group who also failed to show any HLA association. ${ }^{19}$

Various HLA associations with idiopathic dilated cardiomyopathy have been claimed including increases in frequency of DR1 and DR10, ${ }^{14}$ B7, ${ }^{8}$ DR5, ${ }^{10}$ B27, ${ }^{12}$, DR6, and DQ $4,{ }^{11}$ and decreased frequency of DR3, ${ }^{10} 13$ and DR6. ${ }^{12}$ HLA-DR4 was associated with idiopathic dilated cardiomyopathy in some of the studies $^{7-13}$ but not in all. ${ }^{814}$ The metaanalysis also seemed to confirm the association with HLA-DR4. ${ }^{11}$

A hazard of analysis of this type of data is that because of its nature many sets of comparisons are made and this increases considerably the likelihood of producing a spuriously significant association. This may partly explain the large number of different reported associations. In any case none of the reports claims an association that is as strong as in "classic" HLA linkages.

Our results do not establish any HLA linkage with idiopathic dilated cardiomyopathy or ischaemic heart disease. There is no clear reason why our series should be different from those already published, other than possible differences arising from geographically and ethnically different populations. The evidence presented in favour of a link between idiopathic dilated cardiomyopathy and HLA-DR4 is, however, inconclusive: two of the eight studies (one of which has been published since the meta-analysis) failed to show the link, and several studies have shown HLA linkages not confirmed by the others. There were 453 patients in these studies $^{7-14}$ and 361 were included in the metaanalysis. Much more data than these must be available: 19451 heart transplants had been performed worldwide by 31 December $1991^{20}$; most of these will have been HLA typed together with a substantial number of patients who were assessed but did not receive transplants. Forty nine per cent of heart transplants are performed for cardiomyopathy, ${ }^{20}$ and most of these patients will have idiopathic dilated cardiomyopathy. Thus there must be much unpublished data on HLA typing in this condition. This information will be concentrated in transplant centres where comprehensive databases are usually maintained. It may well be, therefore, that other researchers have also failed to show the association but have not considered it worth reporting or have encountered publication bias against negative results.

We also found no association between HLA type and end stage coronary heart disease, but this is less controversial because so far immunological mechanisms have not been implicated in the native disease and only one study to date has suggested a link (with HLADR6). ${ }^{15}$

An immunological basis for idiopathic dilated cardiomyopathy remains likely, but idiopathic dilated cardiomyopathy is probably a heterogeneous condition and it may be that a strong immunological component is not a feature of all subgroups.

1 Anderson JL, Carlquist JF, Hammond EH. Deficien natural killer activity in patients with idiopathic dilated cardiomyopathy. Lancet 1982;ii: 1124-7.

2 Fowles RE, Bieber CP, Stinson EB. Defective in vitro suppressor cell function in idiopathic congestive cardiomyopathy. Circulation 1979;59:483-91.

3 Gerli R, Rambotti P, Spinozzi F, et al. Immunologic studies of peripheral blood from patients with idiopathic dilated cardiomyopathy. Am Heart 7 1986;112:350-5.

4 Wong CY, Woodruff JJ, Woodruff JFR. Generation of cytotoxic $\mathrm{T}$ lymphocytes during coxsackie B-3 infection: II characterisation of effector cells and demonstration of cytotoxicity against viral infected myofibres. $\mathcal{F}$ Immunol 1977;118:1165-9.

5 Limas CJ, Goldenberg IF, Limas C. Autoantibodies against $\beta$ adrenoceptors in human idiopathic dilated cardiomyopathy. Circ Res 1989;64:97-103.

6 Carforio ALP, Bonifacio E, Stewart JT, et al. Novel organ specific circulating cardiac autoantibodies in dilated specific circulating cardiac autoantibodies in dilat

7 Limas CJ, Limas C. HLA antigens in idiopathic dilated Limas CJ, Limas C. HLA antigens in idiopa

8 Zerbe TR, Kaufmann C, Colson Y, Duquesnoy R Associations of HLA-A, B, DR antigens with primary Associations of HLA-A, B, DR antigens with primary
disease in cardiac allograft recipients. $\mathrm{Am} \mathrm{f}$ Cardiol disease in cardiac

9 Komajda M, Raffoux C, Salame E, et al. HLA A-B and DR antigens in dilated cardiomyopathy. Arch Mal Coeur 1987;80:1233-7. 
10 Arbustini E, Gavazzi A, Pozzi R, et al. The morphological spectrum of dilated cardiomyopathy and its relation to immune response genes. Am $¥$ Cardiol 1989;64:991-5.

11 Carlquist JF, Menlove RL, Murray MB, O'Connell JB, Anderson JL. HLA class II (DR and DQ) antigen associations in idiopathic dilated cardiomyopathy. Circulation 1991;83:515-22.

12 Anderson JL, Carlquist JF, Lutz JR, DeWitt CW, Hammond EH. HLA A, B and DR typing in idiopathic dilated cardiomyopathy: a search for immune response factors. $A m$ F Cardiol 1984;53:1326-30.

13 Carforio ALP, Martinetti M, Schwartz G. Idiopathic dilated cardiomyopathy: lack of association between circulating organ specific cardiac antibodies and HLA DR antigens. Tissue Antigens 1992;39:236-40.

14 Maharaj B, Hammond MG. HLA-A, B, DR and DQ antigens in black patients with idiopathic dilated cardiomyopathy. Am $f$ Cardiol 1990;65:1402-3.

15 Limas CJ, Limas C. HLA-DRw6 antigen linkage in chronic congestive heart failure secondary to coronary artery disease (ischaemic cardiomyopathy). $A m \mathcal{F}$ Cardiol 1988;62:816-8.

16 Darke C, Dyer P. Clinical HLA typing by cytotoxicity. In: Dyer P, Middleton D, Histocompatibility testing, a

17 Savage D, Baxter-Lowe L-A, Gorski J, Middleton D. Molecular methods. In: Dyer $P$, Middleton $D$, eds. Histocompatibility testing, a practical approach. Oxford: IRL, 1993:108-42.

18 RD Levy, SCD Grant, S Sheldon, PA Dyer, NH Brooks. Do specific HLA antigens pre-dispose to coronary heart disease or congestive cardiomyopathy [abstr]. Eur Hear $\Im$ 1992;13(suppl): 110 .

19 Harcombe A, Joysey V, Sharples L, et al. Association with primary disease in cardiac transplant recipients [abstr]. Br Heart $\mathcal{F}$ 1993;69(suppl 5):P70.

20 Kaye MP. The registry of the International Society for Heart and Lung Transplantation: 9th official report1992. F Heart and Lung Transplantation 1992;11: 599-606. 